Aloman 2015, 33(1), 79-91

Revista de Psicologia, Ciències de l'Educació i de l'Esport

ISSN: $1138-3194$

Copyright (C) 2015

www.revistaaloma.net

\title{
El joc del «rescat» en el procés constituent de l'esport contemporani a Catalunya (1900-1926)
}

\author{
Jordi Brasó-Rius ${ }^{1}$ \& Xavier Torrebadella-Flix ${ }^{2}$ \\ ${ }^{1}$ Centre d'Alt Rendiment Esportiu de Sant Cugat del Vallès \\ ¿Universitat Autònoma de Barcelona
}

Rebut: 1-10-2014

Acceptat: 7-4-2015

\section{El joc del «rescat» en el procés constituent de l'esport contemporani a Catalunya} (1900-1926)

Resum. L'objecte d'aquest article és analitzar la presència del joc del rescat en la societat catalana $i$, concretament, en els moviments associatius de l'esport d'inicis del segle Xx. Aquest estudi s'ha elaborat a partir d'una recerca documental de fonts primàries, principalment de la premsa esportiva, però ha comptat amb el suport d'altres investigacions recents. A principis del segle passat, amb la incorporació dels esports d'origen anglosaxó, a Catalunya el popular joc d'equip del rescat va presentar-se públicament amb la intenció d'assolir el nivell de reglamentació òptima per ser acollit en el procés de deportivització modern. Així, el rescat va ser practicat a Barcelona per alguns prohoms de la cultura física, agrupant-se inicialment en la «Colla Riscat», i tractant de potenciar el caràcter saludable i educatiu d'aquest joc a l'aire lliure. Així mateix, la pràctica es va exhibir com a expressió genuïna de la catalanitat davant l'allau de les pràctiques esportives foranes que s'estaven duent a terme a Catalunya. Tot i la propaganda i la popularitat ancestral del rescat, aquest joc corporal va perdre l'atractiu predominant en els costums recreatius de la població més jovenívola. Una de les causes de la pèrdua de protagonisme de la pràctica s'atribueix a la ràpida i significativa acceptació de l'esport de moda: el futbol.

Paraules clau: Colla del riscat», joc del rescat, joc del marro, història de l'esport a Catalunya, futbol

The Prisoner's base game and the birth of contemporary sport in Catalonia (1900-1926)

Summary. The purpose of this paper is to study the role of the game called prisoner's base or prisoner's bar in the Catalan society, and specifically that of associative movements involved in the sport in the early $20^{\text {th }}$ century. This study was compiled from documentary research using primary sources, mainly from the sport press, but also makes use of the findings of other recent research. At the beginning of the last century, with the incorporation of English sport in Catalonia, the popular game called prisoner's bar was presented to the public with the intention of achieving the greatest possible degree of as part of modernization of sport. Thus, the game was played by some leaders of the culture of physical activity in Barcelona. These people created an association called «Colla Riscat, with the goal of promoting education and a healthy attitude toward nature. The activity was also depicted as a genuine expression of Catalan-ness, in contrast to the deluge of foreign sports rushing into Catalonia. Despite the associated propaganda and the established of the game, it lost the pride of place it had once held among youth leisure habits. The loss of importance of the activity can be attributed in part to the rapid acceptance of a newly fashionable sport: football.

Keywords: "Colla riscat», prisoner's bar, prisoner's base, history of sport in Catalonia, football

Correspondència

Xavier Torrebadella Flix

Universidad Autónoma de Barcelona

Facultad de Ciencias de la Educación

Departamento de Didáctica de Expresión Musical, Plástica y Corporal

Email: xtorreba@gmail.com 
«¿Perqué sports, quan la paraula deports és tan castiçament catalana?»

(Pons, 1921)

\section{Introducció}

Les restriccions socials i l'oci són dues cares de la mateixa moneda. Elias i Dunning (1986) ja tracten aquesta qüestió. Així, l'espai de relaxació que proporcionen les determinades activitats per esbargir-se, corresponents a cada època, és, a la vegada, controlat per restriccions civilitzadores. La música, el teatre, els jocs i els esports tenen aquesta funció recreativa en la societat. I, pel que fa als jocs i als esports, mitjançant el reglament es crea una ficció que, d'una banda, potencia la relaxació, l'emoció i el plaer, però, d'una altra, també proposa límits. Els jocs representen, per tant, llibertat, invenció, fantasia, simbolisme, però també disciplina i socialització (Caillois, 1986; Huizinga, 1972). Aquests fets relacionats amb la qüestió de crear un món a part de la vida real són els que fan que la societat s'organitzi en agrupacions per tal de practicar jocs i competir entre elles.

Als inicis del segle $\mathrm{xx}$, a Catalunya, la prominent burgesia també s'organitza per practicar diferents formes d'oci. En l'àmbit associatiu apareixen uns moviments per promoure l'esport i determinats jocs corporals. Una d'aquestes pràctiques és el popular joc conegut amb el nom de rescat, que s'intenta propagar en la societat pel seu caràcter saludable, però, sobretot, per fer front a les noves formes d'oci i a les pràctiques esportives importades d'origen anglosaxó, i representades principalment pel futbol.

L'objecte d'aquest estudi és analitzar la presència del joc del rescat en la societat catalana i, concretament, en els moviments associatius de l'esport d'inicis del segle xx. En un inici s'analitzen els diferents mots que va prendre el joc segons el territori català, ja que moltes zones el van prendre com a activitat pròpia de la localitat ${ }^{1}$. Posteriorment s'analitzen els primers intents d'associacionisme, que van tenir a la «Colla Riscat» com a màxima promotora de la pràctica. A continuació es reflexiona sobre els intents d'alguns personatges per promocionar el joc, justificant el seu simbolisme català, a més dels seus beneficis saludables i educatius. Es tracta, finalment, la progressiva pèrdua de protagonisme d'aquesta pràctica lúdica fins al punt de quedar gairebé extingida.

Per a la recerca s'han utilitzat les principals bases de dades de la premsa històrica catalana digitalitzada. Els catàlegs col-lectius del Departament de Cultura de la Generalitat de Catalunya [www.xacpremsa.cultura. gencat.cat] i l'Arxiu de Revistes Catalanes Antigues (ARCA) de la Biblioteca de Catalunya [www.bnc.cat/ digital/arca]. També s'han establert recerques a l'hemeroteca digitalitzada de La Vanguardia i El Mundo Depor-

${ }^{1}$ En aquest article emprarem les paraules rescat i riscat indistintament. A més, aquest joc és també conegut amb el nom de marro. tivo. Finalment, per contextualitzar el joc del rescat en la societat catalana, s'han tingut en compte les obres i els estudis de diferents especialistes en l'àmbit de la història social de l'esport.

\section{Contextualització}

Els orígens de l'esport modern a Catalunya tenen l'arrel en els esports d'origen anglosaxó. No obstant això, en el període que va de les acaballes del segle xix a les primeries del segle $\mathrm{xx}$, apareix una situació de transició en la qual la incorporació dels nous esports rivalitza amb aquells jocs o deports de caràcter nacional. D'aquesta manera, i com citen diversos autors (Elias \& Dunning, 1986; Mandell, 1986; Rivero \& Sánchez, 2011; Valserra, 1944), allà on van arribar els elements de la colònia britànica també hi va penetrar l'esport modern. Es pot dir que, de totes les localitats d'Espanya, Barcelona va ser l'epicentre de la principal concentració i experimentació d'aquesta transformació social que anava paral-lela al desenvolupament industrial i econòmic de la ciutat (Hip, 1917; Lagardera, 1992, 1996; Pujadas \& Santacana, 2001, 2003; Torrebadella, 2012b; Torrebadella \& Olivera, 2013).

L'emergent burgesia de Barcelona prenia les referències de la societat victorina, que arreu del món exportava un estil de vida elitista en el qual l'esport era la màxima expressió. No obstant això, a Catalunya aquest fet topava amb el moviment cultural de la Renaixença, representat per un col-lectiu d'institucions que no volien perdre les identitats ni les arrels de la catalanitat. En el 1880, el primer Congrés Catalanista promogut per Valentí Almirall va portar a l'escenari de la política les reivindicacions nacionals. La burgesia industrial no participava del moviment catalanista ja que aquest estava representat per col-lectius de professionals liberals i comerciants (Balcells, 1992). Com citen Pujadas i Santacana (1992, p. 78), hem d'atendre que «els inicis de l'esport català coincideixen cronològicament amb l'etapa de la progressiva formulació teòrica del catalanisme polític». Tot i això, aquests autors no troben cap influència ni cap sensibilitat pel fet nacionalista i subscriuen l'esport català en el marc ideològic de l'esport espanyol. Doncs, tant és així, que les principals iniciatives d'integrar un associacionisme esportiu d'Estat van sorgir des de Barcelona, principalment liderades per Narcís Masferrer, que feia de pont entre els promotors esportius de Barcelona i Madrid (Pujadas \& Santacana, 1992; Torrebadella, 2012b). Com cita Artells (1972, p. 33) «l'esport a la península havia nascut a Catalunya i era expandit i estimulat d'aquí estant»; tot i això, hi va haver elements que es van dedicar «a separar l'esport de qualsevol contacte amb el catalanisme militant i actiu». No obstant això, hem de coincidir amb Pujadas (2008, p. 22), que opina que, a partir del segle passat, «la identificació entre catalanisme polític, regeneració i esport va ser relativament ràpida».

Cal dir, però, que en aquest procés de deportivització hem de fer algunes objeccions. Com citen alguns autors, els jocs, els esports o els deports sempre han estat 
presents en la tradició catalana (Artells, 1972; Hip, 1917; Pons, 1921; Serra, 1923; Torrebadella \& Planas, 2011). En el cas de l'esport, sí que hi havia una presència del catalanisme; tot i que no sempre estava relacionat amb l'aspecte polític, sí que almenys amb una perceptible empremta cultural. Aquesta característica l'hem de cercar, com s'ha comentat, en el moviment literari de la Renaixença i en una pràctica deportiva que afavoreix la primera literatura excursionista. L'Associació Catalana d'Excursions Científiques, creada el 1876, i les successores entitats excursionistes d'arreu de Catalunya, en aquests primers anys són una mostra al-legòrica de les arrels d'aquest incipient esport. La literatura excursionista des d'Artur Osona, Jacint Verdaguer, Bosch de la Trinxeria, Francesc Maspons, Lluís Marià, Joaquín Morelló o Juli Soler (Torrebadella, 2011), assenten les bases d'aquest excursionisme novell que, al capdavall, esdevindrà el principal esport, símbol i custodia de la identitat catalanista.

De la tradició catalanista sorgeixen impulsors de la Renaixença lleidatana. Així, Lluís Roca Florejachs (Borrell i Sanvicén, 1998) presentà en els primers Jocs Florals de Barcelona, l'any 1859, «Los cóssos. Festa popular». Anys més tard, en els Jocs Florals de 1903, un altre poema «Lo cós de la Cordera», de Josep Iglesies Guizard, obtingué un segon accèssit (Capdevila, 2012). La popularitat dels cóssos forma part d'aquestes proves atlètiques, del deport genuïnament català que esmenta Josep Maria Romagosa (Font d'Horta, 1921). En aquesta etapa de transició, un exemple ve representant per alguns destacats corredors de cóssos com l'arbequí Boneventura Tilló, el primer classificat nacional en la primera gran cursa atlètica que es va organitzar a Barcelona per part d'El Mundo Deportivo el 1907 (Torrebadella, 2003).

La catalanitat es copsava en una preocupació per la llengua. Així, davant l'emergent terminologia de l'esport, L'Esquella de la Torratxa posava en relleu el malestar per la invasió de mots estrangers (Extrangerisme, 1901): «Va posantse de tal modo el nostre idioma d'un quant temps a aquesta part, que si las autoritats... académicas no prenen per sapiguer lo que llegim ni lo que ens pesquem... Pero comensarem a introduirse entre nosaltres els sports extrangers y jadios idioma! L'habla de Cervantes queda feta un guinyapo y la llengua del rector de Vallfogona un drapot» (J. B., 1902).

A més, aquest catalanisme popular tenia també la seva identificació en els representants de l'església catòlica. Fins i tot parlava de l'esport en català Félix Sardà (1908) en L'sport católich, La Salle de Rochemaure (1909) en Los sports i llur influència en el caràcter, o Torras i Bages (1910) en L'atletisme cristià.

Així, doncs, en aquest període de culturització de les recreacions deportives o jocs nacionals, com cita Bourdieu (2008), l'esport anglosaxó es va dotar d'elements de distinció social i amb el seu suport va fixar i regular els codis simbòlics en l'estil de vida de la classe benestant. Conseqüentment, van ser les classes més afavorides les que van potenciar les noves pràctiques esportives com a fet diferencial d'exercitar símbols de poder sobre les classes populars i en van gaudir. En aquest xoc cultural, i per fer front a les noves pràctiques esportives anglosaxones, van ser els jocs, o els nostres deports nacionals, que citava Narcís Masferrer (1917, p. 6), els que, sense cap reglamentació i només conciliats sota la paraula tramesa entre generacions, van quedar exclosos del seu grau de sentit antropològic i social que els arrelava al poble (Artells, 1972; Pastor, 1998).

\section{L'esport modern a Catalunya i el regeneracionisme}

A Catalunya, des de finals del segle xIx, el concepte de regeneracionisme aixopluga també una àmplia diversitat de doctrines de l'associacionisme esportiu. L'embranzida de l'esport modern que experimenta la Barcelona de finals de segle XIx i principis del segle xx ha quedat imbuïda per una forta impregnació de l'herència de l'estil de vida victorià. L'esport anglosaxó té una àmplia presència en els afers socials de l'elitista classe dirigent, que és representada per una burgesia que s'ha enriquit en pocs anys gràcies al desplegament industrial de les darreres dècades. No obstant això, aquest associacionisme elitista va tenir una esperitosa oposició amb la presència d'entitats de caire popular i de classe mitjana -l'Ateneu Enciclopèdic Popular (AEP) i el Centre Autonomista de Dependents del Comerç i de la Indústria (CADCI)- que van enfrontar-se com a reacció a l'onada d'influències colonials d'Anglaterra que també es feien sentir en l'esport. L'època modernista va omplir-se, esperonada pel moviment cultual de la Renaixença, d'un sentiment de catalanitat, que, sovint, va ser utilitzat pels diferents grups polítics, principalment per la Lliga Regionalista. Política, catalanitat, cultura física i una forta identificació cultural d'arrel popular també s'empeltaven de les manifestacions de l'associacionisme esportiu.

En l'escalf d'aquest ambient, a Barcelona hi ha una persona que lidera un discurs ideològic en el qual l'esport es presenta com un mitjà eficaç per a la regeneració i la defensa de la identitat nacional. Es tracta de Josep Elias i Juncosa (1880-1944), un jove aficionat als esports que compagina la seva feina a la banca amb les iniciatives més reeixides en el periodisme esportiu escrit en català. A principis de segle, Josep Elias en la Ilustració Llevantina va posar en relleu l'embranzida que l'esport estava protagonitzant a Barcelona. Argumentava la necessitat que hi havia a Catalunya de practicar esport, ja que, deia que «la força individual fa la de les nacions» (Elias, 1900, p. 1):

Es indubtablement que a la nostra ciutat que marxa en lo que's refereix al moviment sportiu, com en altres ordres, al cap de les demés poblacions d'Espanya, l'esperit practich de la gent de casa ha sabut reconèixer les ventajes de tot exercici pel cos, lo que fa que aqui'ls practiqui tot mes o menos, arrivant alguns d'ells a arrelarse en les costums de la gent sportiva catalana. (Elias, 1901, p. 1)

Doncs, pel que fa als esmentats costums i a la pràctica dels novells modes d'exercitació física, Elias (1900, 
p. 2) aclaria el fresc anglicisme: «diguém qué s'enten per SPORT (aquest mot tan empleat avuy dia que molts no sabem lo que vol dir) tot exercici al ayre lliure, nom que ve del inglés, alteració de «disport»y aquest del antich frances millor, vell català) «deport», o sia divertiment» (Torrebadella \& Planas, 2011). Així, entre els deports més emblemàtics que hi havia a Catalunya, el del rescat era un dels més practicats pels joves i, per tant, era portador dels signes populars i de catalanitat que s'arrelaven en el poble, com més endavant es comentarà.

En Sebastià Farnés (1902) parlava del fet que «la idea catalanista va fent camí», per assolir la «reconstitució de la Pàtria catalana» (p. 5-6). Aquesta era una manifestació que en l'àmbit dels esports prenia identitat en les paraules de Josep Elias (1902) quan expressava que «del verdader camí de regeneració» (p. 156) «Catalunya, lo primer poble de Espanya, per son caràcter especial ha sigut y es la regió que ha anat sempre al davant de totes en lo que's refereix a la pràctica de la educació física» (Elias, 1902, p. 155-156).

Josep Elias, conegut amb el pseudònim de «corredisses» des de La Veu de Catalunya, es va erigir com el portaveu de la Lliga Regionalista pel que fa a les qüestions d'esport i educació física. A partir de 1903 també va ser el redactor de la secció d'esports del setmanari La Ilustració Catalana, activitat que va iniciar el 7 de juny de 1903, signant els articles només amb la inicial del seu nom. El seu discurs es va situar en el catalanisme moderat (Elias, 1992). Per a Alexandre Galí (1985), Josep Elias va ser un dels clars referents en la lluita pel «desenvolupament de l'esport i per la cultura física en general» que va cobrir de forma il.lustrada i conscient tot el primer quart del segle passat (p. 181).

Destaquem també, que la tasca periodística de Josep Elias va contribuir a forjar el primer vocabulari català de l'esport. El seu coneixement esportiu el va dur a col-laborar també en la premsa especialitzada de l'època, que, principalment, s'editava en castellà.

El segle xx s'inaugurà amb el que va ser la primera participació catalana en els Jocs Olímpics de París, amb els remers del Reial Club de Regates de Barcelona. En aquest mateix any, les Festes Federals de la Segona Assemblea de la Federación Gimnástica Española (1900), coincidint amb les Festes de la Mercè, mostren el potencial esportiu de Barcelona. A partir d'aleshores, l'esport en les Festes de la Mercè serà un dels principals protagonistes, amb pràctiques de lawn tennis, ciclisme, football, gimnàstica artística, hípica, tir, esgrima, rem o un concurs hípic.

A Barcelona s'estava creant un ambient esportiu sense precedents (Pujadas \& Santacana, 1995). Amb poc més de dos anys el futbol havia esdevingut un motor per a l'educació física dels joves. Josep Elias se'n feia ressò en $\mathrm{La}$ Veu de Catalunya: «dirém que la gran importància y l'afició a n'aquest sport que hi ha en tots els països civilitzats, repercuteix a Barcelona, ahont hi há una vintena de Clubs, dedicats exclussivament a practicarlo, contant ab més d'un miler de socis y jugantse cada festa en més d'una dotzena de camps de joch que fins al present hi ha instalats a la nostra ciutat» (Corredisses, 1902, p. 2).

El motor industrial, social i cultural de Catalunya donava també un bon exemple del boom de l'afició als esports que, com el futbol, no van trigar gaire a escampar-se per totes les poblacions catalanes. Aquest caliu era copsat per Josep Elias (1903) en La Ilustració Catalana:

Diferents vegades ens hem ocupat de la propagació dels Sports a la nostra ciutat i de la popularització d'alguns d'ells, més visible cada dia. Això pot aplicar-se al jòch del futbol, que no solament practica mes de 1.500 jugadors, agrupats en més de trenta Clubs, sinó que per tots els xamfrans del Esanxe se veuen xicots jugant amb pilotes més o menys futbolístiques.

Ademés d'aixó, la plaça de Catalunya està convertida cada vespre en un camp de jòch (a falta d'altres que l'Ajuntament deuria curar-se d'establir), vegentshi animats partits amb totes les regles del jòch. (Elias, 1903, p. 259)

L'emergència social de l'esport donà peu a la creació de les primeres associacions d'entitats. A Barcelona, l'any 1903 es creen l'Associació Clubs de Foot-ball i l'Associació de Lawn-tennis. En pocs anys es van anar constituint altres associacions i federacions esportives. L'ambient esportiu i gimnàstic que es generava a Barcelona també es va contagiar arreu del principat. En aquests anys, l'esport i la gimnàstica esdevenien socialment elements de cultura i de regeneració física i tenien un component modernista i d'avantguarda (Pujadas \& Santacana, 1995).

Durant aquests primers anys del segle xx, el Sportmen's Club (1903-1906) va esdevenir l'element promotor d'una infinitat de pràctiques esportives. En aquesta associació hi estaven representats els joves de les classes més benestants de Barcelona. Amb poc temps van assajar nous esports i van organitzar festivals esportius, exhibicions i campionats de tota mena. Però, per a transmetre l'activitat i l'energia de totes aquestes iniciatives, calien més mitjans de propaganda.

A finals del 1903, Josep Elias (1904) ja parlava de la popularització dels esports a Barcelona, que, gràcies sobretot al futbol, s'estava incorporant en les classes populars, «trobant en l'esport lo verdader socialisme» (p. 119), i de com totes aquestes energies s'estenien cap a tot Catalunya «forman de la joventut sportiva un exércit de defensors ferms de Catalunya; per apoyarla en tots los ordres lo dia de demá» (p. 119-120).

Elias (1905) comprovava com l'esport anava consolidant protagonisme arreu del Principat i com també la premsa col-laborava en tot aquest entusiasme regeneracionista:

En general lo moviment creix cada dia no sols aquí sinó que es molt important, en gran numero de publicacions del restant de Catalunya, fins en algunes de petita importància en totes les quals s'han celebrat festes de bicicletes, futbol, carreres a peu, regates, patinatge; etc., etc., estenentse per tot la propaganda dels sports (Elias, 1905, p. 121). 
Així, per a cobrir tota l'oferta esportiva de Catalunya, l'1 de febrer de 1906 sortí el setmanari El Mundo Deportivo, fundat por Jaume Sala i dirigit per Narcís Masferrer. En l'editorial es deia «contribuiremos por otra parte con todos nuestros alientos a propagar la excelencia de los ejercicios físicos, la práctica de todos los deportes, de toda clase de juegos» (p. 1). El Mundo Deportivo va promoure nombroses associacions i competicions esportives i va tenir la deferència d'incloure les noticies que s'anaven produint arreu de Catalunya (Pujadas \& Santacana, 1997).

El 15 de febrer de 1908 va néixer el setmanari Sports -revista Catalana d'Educació Física-, la primera revista escrita exclusivament en llengua catalana. Dirigida por Joan Sunyé, tan sols van ser publicats cinc números fins al 14 de març:

$\mathrm{Al}$ aparexe la nostra revista redactada en català no té cap altra significació que la de respondre a la realització, dintre de la premsa catalana, d'una missió eminentment educativa.[...]

Avui a Catalunya i principalment Barcelona, existeix ja un moviment sportiu prou important, y per aixó-ls que fem SPORTS hem cregut arribat el moment de publicar una revista catalana que recollint aquestes palpitacions de vida, orienti degudament les nostres manifestacions d'educació física, contribuint aixis, a l'obra de cultura integral que s'està realitzant venturosament a Catalunya (Torrent \& Tasis, 1996, p. 465-466).

En el nou segle, la progressiva manifestació dels esports va anar consolidant organitzacions i campionats oficials. La proliferació dels esports i de l'associacionisme va anar també acompanyada de la popularització i de la propaganda d'una premsa esportiva, cada cop més especialitzada i que tenia com a model Los Deportes (Pujadas \& Santacana, 1995; Torrebadella, 2012a).

Com tracten Pujadas i Santacana (1995), el panorama de l'esport català s'enriquia amb noves associacions, però especialment a Barcelona, en la primera dècada del segle, on van néixer noves entitats i nous esports. Sense citar les nombroses entitats futbolístiques, són d'aquesta època: Real Societat de tennis Pompeya (1905), Real Automòbil Club de Catalunya (1906), Real Societat d'Esport Basc (1906), Club Natació Barcelona (1907), Barcelona Hockey Club (1907), Secció d'Esports de Muntanya del CEC (1908), Solé Pedestre Club (1908), Real Club Nàutic de Barcelona (1909) o Club Pugilístic de Barcelona (1910).

La dona també s'inicià en les pràctiques esportives. L'equitació, l'excursionisme, la gimnàstica sueca, el patinatge o el tennis van ser els primers esports on la dona es va obrir camí. Així ho manifestava Josep Elias (1907) dient que «el sport havia arribat a gran altura a Barcelona, i sols li faltava la consagració que la dona li ha donat, per a que pugui figurar definitivament en les nostres costums» (p. 7).

L'esport havia entrat en els principals col-legis de la burgesia catalana, principalment en les escoles de les congregacions catòliques. L'església s'havia fixat en aquest fet i el volgué aprofitar. Figures influents com Félix Sardà Salvany es van pronunciar a favor dels esports, ja que, per mitjà de la seva pràctica, veien com podien acostar els joves a les creences religioses i apartar-los dels vicis i de les males pràctiques socials. Sardà proposava:

(...) aixecar a tot arreu centres de sport honrat i digne... D'exa manera el Centre sportiu pot considerar-se, i ja es considera en molts punts del estranger, com verdader germà i braç pret de la parròquia, com una verdadera dependència parroquial, com una obra del parroquialisme en tota la propietat de la paraula (Sardà, 1908, p. 13-14).

Val a dir, però, que Sardà també desitjava contrarestar les activitats proselitistes de les entitats i ateneus llibertaris, de l'esquerra política i sindicalista revolucionària.

El balanç esportiu de la primera dècada del segle xx va ser força positiu per als interessos de l'esport català. El futbol s'havia consolidat com la icona de la revolució de l'esport popular. L'any 1910 una poderosa Federació Catalana de Clubs de Foot-ball va decidir formar part de la Federació Española sempre que mantingués la seva sobirania pel que fa a les decisions catalanes (Pujadas \& Santacana, 1992).

\section{El joc o deport del rescat en la tradició popular catalana}

El joc motriu del riscat va adoptar trets singulars i diferents noms segons el territori en el qual es practicava. A Catalunya era conegut inicialment com a moros $i$ cristians i, posteriorment, amb el nom de riscat, rescat, o també amb els seus plurals corresponents. Així, diversos són els escrits que anomenen amb diferents mots el joc, o que analitzen els seus orígens lingüístics (Blai, 1919; Esteve \& Belvitges, 1803; Labernia, 1865; Maspons, 1874; Miscelánea, 1900a Moll, 1951; Pelegrín, 1998; Rovira, 1926; Societat de Catalans, 1839). Es comprova, però, que, a finals del segle xIx i fins ben entrat el segle $\mathrm{xx}$, el joc prengué el nom català de riscat o rescat. A més, va ser símbol de catalanitat en aquesta època d'enlluernament social de l'esport anglosaxó. Aquest fet s'explica per la voluntat d'un grup de joves per no perdre l'essència dels jocs tradicionals i populars més arrelats als costums catalans.

Veurem, doncs, com aquest exercici va ser practicat a Barcelona i va entrar en un incipient procés d'esportivització, que, al cap i a la fi, no va reeixir.

És així, doncs, que la pràctica d'aquest joc a Catalunya, juntament amb el moviment associatiu esportiu d'inicis del segle $\mathrm{xx}$, fan que, des d'alguns sectors, es pretingui promocionar el joc del rescat i generalitzar-lo a la població, tant pels seus beneficis, com per fer front a la introducció i expansió de l'esport estranger que cada vegada era més present a les terres catalanes. L'Associació Catalana de Gimnàstica és una de les entitats principals que fomenten aquesta pràctica, junta- 
ment amb personatges que plasmen les seves idees relacionades amb el fet de convertir el rescat en un esport i habilitar espais per a aquest ús (Blai, 1919; Georgina 1919; Regàs, 1929).

Els inicis de l'associacionisme esportiu del rescat es poden ubicar en el mes de febrer de 1900 al gimnàs Solé. Cal incidir en la funció social i esportiva que el citat gimnàs significà, tal com destaquen Picornell, Elias, Gamper o Masferrer. D'aquesta manera, el gimnàs fou un lloc de promoció de l'activitat física, és a dir, «ha estat un lloc on s'ha rendit culte a la cultura física en tots els seus aspectes i amb el major desinterès ha acollit sempre tota mena d'entitats esportives, ajudant-les amorosament» (La cuna del C.N. Barcelona, 1927, p. 19). A més:

(...) de dicho centro importantísimo han surgido entidades, organismos y sociedades deportivas que han conservado y difundido por todas partes el entusiasmo y la afición á los más saludables ejercicios físicos. La «Asociación Catalana de Gimnástica», la revista Los Deportes, muchas agrupaciones de excursionistas á pie y en bicicleta; de atletismo, riscat, foot-ball, esgrima al aire libre, natación y tantas otras, que sería prolijo enumerar (Gimnasio Solé, 1904, p. 683).

Fou en aquest gimnàs, concretament al tauler de l'Associació Catalana de Gimnàstica, on s'iniciava l'associacionisme en l'àmbit del joc del rescat, mitjançant un escrit que demanava adeptes per formar un grup de practicants, tenint en compte els beneficis que comportava per a la salut i l'estat d'ànim que aquest joc practicat a l'aire lliure comportava. A la vegada, es justificava el seu ús detallant que era més sa que els esports estrangers que s'estaven posant de moda. Per tant, la crida també tenia un caràcter marcadament nacional català, ja que hi havia la voluntat de potenciar les pràctiques tradicionals. En paraules textuals, la nota a la qual ens referim i que detalla el que s'acaba d'esmentar, és la següent:

Tenint en compte la necessitat de practicar assíduament un ejercici corporal al aire lliure, que proporcioni salut al cos é grat espargi al ánima, n’havem pensat formar una colla anomenada del «Riscat» é que com aytal non indica tindrá per objecte practicar algunas voltas cada mes, tan conegut joch, superior per varies rahons á molts deis anomenats sports que avuy dia's practiquen més per lo que tenen d'extrangers que per lo bons que resulten.

Vos convidem, donchs, á formar en tal Colla, é esperem de vosaltres la més decidida cooperació per aclimatar entre nosaltres aytal joch, més sá é sobretot més català, que tots los que avuy sols per ser extrangers están de moda (Miscelánea, 1900a, p. 125).

A més, el redactor-periodista que inclou la nota anterior en Los Deportes destaca, que amb el nombre que hi ha de subscripcions, en breu s'organitzarà «el primer partido de marro, ó sea el Riscat catalán» (Miscelánea, 1900a, p. 125). Aquests inicis de la Colla Riscat, que tingué la seu també al gimnàs Solé, van culminar amb el primer partit a Barcelona, el dia 11 de març de 1900 , fet que més tard va significar un acte recordat i significatiu (Estos días en otros tiempos, 1917, p. 166).

Per tant, a principis del segle xx, un grup de joves de l'Associació Catalana de Gimnàstica creen la Colla Riscat i inicien un moviment social que practica i promou el joc, considerat superior als esports estrangers. Els objectius principals de la colla eren, a més de reforçar la salut física i mental, promoure el joc com a símbol d'un «sport genuinamente catalán» (Un Riscatista, 1900e, p. 374). Tots aquests fets fan que, a Barcelona, alguns aficionats sportsmen intentin reglar el joc amb la intenció d'institucionalitzar-lo pròpiament com a esport.

Durant la primavera de 1900 es duen a terme els primers assajos del joc del riscat. El partit inaugural va ser celebrat l'onze de març, enfrontant l'equip dels Vermells contra els Blaus -aquests eren també els colors per a diferenciar els primers partits de futbol disputats a Barcelona (Torrebadella, 2012c)-, així com altres esports. L'èxit de l'esdeveniment va portar l'organització a promoure altres interessants trobades, presenciades totes elles per un nombrós públic (Un Riscatista, 1900a). Els partits es van dur a terme al velòdrom o (al) Club Ciclista, propietat d'Andrés Corral -velòdrom de la Bonanova-. Entre els jugadors hi havia «personas distinguidas, de fina educación y discreción extremas, médicos, ingenieros, comerciantes, artistas y sportsmen» (Un Riscatista, 1900e, p. 373). Entre aquests joves hem identificat Josep Elias, Henry Chalande, el Dr. Pere Cercós -president de la FCG i fundador de la FGE-, Jaume Vila -professor de gimnàstica i fundador del Català FC-, Ramon Casas -conegut pintor modernistai Jaume Irla (Un Riscatista, 1900a, 1900b, 1900c, 1900d). Com podem comprovar, en el joc del riscat, hi havia alguns dels promotors del futbol català, com ara el ja citat Josep Elias, Jaume Irla o Jaume Vila.

Jaume Irla i Vert (1882-1906), estudiant d'arquitectura, va ser un destacat sportsmen que va exercitar-se en la gimnàstica, el ciclisme, la natació i el marro. Va ser fundador, president i capità -davanter extrem dretde l'Iberia FC, equip que va integrar els clubs Puchet i Penitente. D'ell es deia que era un «jugador de mucha resistencia, agilidad, combinación y sobre todo gran golpe de vista. Se distingue por su elegancia en el juego y por el modo de engañar con driblings á los contrariOS» (Silueta del primer team Iberia Foot-ball Club, 1903, p. 69). Va ser Secretari de la Unión Velocipédica Española i morí el 1906 d'una llarga malaltia.

La presència de Jaume Vila explica que el joc tingués continuïtat en els campionats atlètics que organitzava l'associació esportiva del Gimnàs Vila, el Català Sport Club (Fiesta Atlética del Catalá Sport Club, 1908). Així mateix, Vila va ser professor de gimnàstica de l'Escola de Mestres (1906-1910) de Joan Bardina, lloc on es van formar mestres com Pere Vergés (Torrebadella, 2013), el qual va introduir el rescat a l'Escola del Mar (Brasó \& Torrebadella, 2014). Bardina, a l'Escola de Mestres, va potenciar els jocs d'equip com el riscat, que 
també l'introduïa en les llargues excursions. Bardina afirmava que la regeneració de Catalunya havia d'anar esperonada per l'educació física dels joves (Bardina, 1908; Delgado, Cortada, González-Agàpito \& Lozano, 1980).

En el cas de Josep Elias, aquest va ser un dels homes més influents de l'ambient esportiu de principis del segle xx. Autor de nombrosos articles i d'algunes monografies esportives, va manifestar un interès propagandístic per la revaloració de l'educació física i l'esport, va introduir en totes les seves obres periodístiques $i$ tècniques aspectes pedagògics i didàctics de notable interès. Va col-laborar en Los Deportes (1897-1910), en El Mundo Deportivo i en gairebé tots els diaris esportius de l'època. A més, Josep Elias, va ser un complet esportista i un directiu, que va animar i va participar en la creació de multitud de clubs i federacions esportives. En aquests primers anys va destacar en la constitució del Futbol Club Barcelona (1899), en l'organització de la Unión Velocipédica Española -de la qual va ser vicecònsol del Comitè Central el 1902-, en la creació de la secció d'esports de la Lliga Regionalista (1904), en la fundació del Catalunya Lawn Tennis Club (1906) -figurant com a soci d'honor- o en la fundació del Club Natació Barcelona (1907). També va participar en la creació de la secció d'esports de muntanya del Centre Excursionista de Catalunya (1908) i va ser fundador i vicepresident del Reial Club Marítim de Barcelona (1909).

En La Veu de Catalunya, el 1899, l'sportsman Josep Elias ja havia iniciat la seva col-laboració periodística, que també va desenvolupar a partir de 1903 en la Ilustració Catalana, en la columna «Sport», signant amb la inicial E. A partir de 1901 va passar a formar part de la redacció, cobrint les notícies relacionades amb l'esport. Josep Elias, també es va comprometre en la campanya d'apostolat del moviment olímpic internacional que liderava el baró Pierre de Coubertin, col-laborant amb la premsa especialitzada (Coubertin, 2004; Santacana, 2004). L'any1909 va ser nomenat director de la pàgina esportiva de La Veu de Catalunya (Balius, 1982; Elias, 1992).

A més, aquest impuls també té el suport de la Federación Española de Gimnástica (FGE), iniciada pels sportsmen catalans de l'Associació Catalana de Gimnàstica, que valora l'esforç de la Colla del Riscat, a part de promoure esdeveniments en els quals apareix el riscat en les festes d'aquesta federació, tant per a grans com per a joves (Fiestas de la Federación Gimnática Española, 1900a, 1900b; Notas locales, 1900, 1902; Programa de festejos para hoy, 1902). Així mateix, l'Associació Catalana de Gimnàstica potencia el joc en altres seccions, com en la Colla Excursionista, la qual pretén practicar el «deporte en general en el medio más sano: el campo» (Arnal, 1900, p. 677). Fins i tot, es pretén que hi hagi una fusió amb la Colla Riscat, mitjançant la sessió del concurs que organitza aquesta última Colla i, també, popularitzar i fer accessible la pràctica als màxims sectors de la població. Per tant, el riscat passa a formar part de les activitats al medi natural, fet que es plasma el diumenge 11 de novembre de 1900 en un seguit de sortides a la muntanya en les quals es practica el joc entre altres pràctiques (Andarín, 1900; Miscelánea, 1900b; Miscelánea, 1900c).

La promoció del joc no era únicament en l'àmbit dels esdeveniments; és a dir, en el camp de joc. La premsa i, molt especialment, el periòdic esportiu Los Deportes, a través de l'Associació Catalana de Gimnàstica, s'encarregava també de promoure el rescat entre els seus lectors. D'aquesta manera, se citava que el joc a l'aire lliure del marro era un excel-lent mitjà d'educació física que contribuïa al:

(...) progreso material y moral de nuestra raza. Todo en él es gimnasia higiénica, gimnasia de piernas y de brazos, gimnasia de pulmones, gimnasia de cerebro, y por él se despierta la emulación, el noble deseo de aventajar al contrario en fuerza de músculos para correr y en fuerza de inteligencia para combinar y realizar la batalla. Acostumbra a la disciplina y a la sumisión espontánea al capitán que el bando pro sufragio libérrimo ha elegido; aparta, por la afición que ocasiona a los que lo practican, de sitios de vicio altamente peligrosos en la edad adulta y mucho más en las grandes capitales, y por último, por él se fraguan los lazos de verdadera amistad, pues nace el calor de las ideas levantadas y puras y de costumbres viriles y morales por excelencia (Un Riscatista, 1900e; p. 373).

En el mateix any 1900, a les Festes Federals de la Segona Assemblea de la FGE, celebrades coincidint amb les festes de la Mercè, ja anunciaven l'emergència per promocionar l'esport barceloní de principis del segle xx. La Colla Riscat, la Societat Esportiva Santanach, el Foot-ball Club Català, el Foot-ball Club Barcelona i les associacions ciclistes de la ciutat tenien la intenció que les festes esportives fossin un èxit rotund. Entre el programa esportiu es va programar una partida de riscat al velòdrom de la Bonanova (Fiestas de la Federación Gimnástica Española, 1900a, 1900b).

Sens dubte, la FGE, constituïda a Catalunya per iniciativa de Narcís Masferrer el 1898, va ser la principal institució que va assumir el protagonisme d'introduir i estendre les pràctiques esportives a Espanya. Durant la seva existència, la FGE va organitzar nombrosos festivals esportius amb l'objectiu de fer propaganda i promoure els nous esports. Un d'aquests exemples va ser el formidable programa de concursos que es van realitzar, sota els auspicis de l'Ajuntament de Barcelona, en les Fires i Festes populars de Ntra. Sra. de la Mercè els dies 24, 27 i 28 de setembre de 1902. La FGE va mostrar una àmplia capacitat organitzativa $i$ l'esdeveniment va significar la primera gran exhibició popular de l'esport espanyol. En aquest programa s'hi van incloure esports atlètics com els següents: curses de tot tipus, llançaments de pes i disc, salts d'alçada, garrotxa, lawn tennis, ciclisme, football, gimnàstica artística, hípica i altres pràctiques esportives. A més, s'hi van incloure jocs escolars per a nens i nenes. D'aquests jocs, el rescat va ser el que va tenir més al-licient. A més, els premis que s'obtenien eren joguines: 
Este juego para niños se desarrollará en una superficie de 40 metros longitud por 30 ancho. Los bandos deberán constar de 8 jugadores cada uno. Los prisioneros se colocaran a 3 metros y en la parte media anterior del bando que los ha capturado. Cada bando tendrá un capitán, cuya prisión señala la victoria del bando que la realiza y la terminación del partido. Será ganado un partido por el bando que logre cinco prisioneros aunque no lo sea el capitán. Cada jugador deberá llevar en el brazo derecho una cinta de igual color para los de cada bando y otro distintivo los capitanes, que será una banderita del propio color. Duración del partido: 20 minutos, después de cuyo tiempo se considerará empate si no se ha cumplido ninguna de las dos condiciones mencionadas. Los primeros números del bando vencedor recibirán los premios anunciados (Federación Gimnástica Española, 1902, p. 11-12).

El joc es va anar practicant en aquests inicis del segle xx. La Colla Riscat -i en menor mesura l'Associació Catalana de Gimnàstica-, per tant, també va en va continuar promocionant la pràctica alguns anys més i ocupant nous espais de joc. Caldria fer esment que aquesta agrupació tenia multitud de socis que miraven els partits i que participaven en altres activitats alternatives organitzades per la Colla. A tall d'exemple, es destaquen les sortides a peu pels voltants de Barcelona, proposades pels caps de la Colla (Corredisses, 1900). Per tant, l'entitat no es va limitar a practicar únicament el joc pel qual havia estat constituïda, sinó que ampliava l'oferta esportiva per als socis.

Entre els equips de football d'aquell temps abans dels partits també es tenia el costum de disputar algunes partides de rescat. Entre aquests equips hi podem trobar el ja citat Català FC i el FC Barcelona (Foot-ball, 1900). És a dir, que el joc del rescat era també presenciat pel nombrós públic d'aleshores.

Pel que fa al velòdrom del carrer Aragó, l'interior havia quedat petit per jugar a futbol i Albert Serra, director esportiu de La Vanguardia, suggeria que en aquest cas podia ser utilitzat per a disputar partides de tennis i de riscat (Serra, 1900). Així, doncs, la deportivització del rescat passava per la voluntat promotora en la construcció de camps de joc, la impressió de reglaments, etc., opinió similar a la que ja hi havia des de feia dues dècades (Un Suplente, 1904).

\section{El joc del riscat, símbol d'identitat catalana}

Cal remarcar la funció d'identitat catalana que va significar la pràctica del joc. D'aquesta manera, per a alguns personatges, el rescat era considerat un «esport català» (Antich, 1904; Georgina; 1919). A l'Avinguda del Tibidabo, on també hi havia assídues partides, es demanava l'existència d'un terreny de joc propi per a aquest «deporte que quizás no exista ningún catalán que no lo haya practicado en su juventud y que sería digno de contar con un Club ad-hoc que cuidara de la organización de partidos y hasta de campeonatos» (Un Suplente, 1904, p. 6).
El rescat va ser practicat durant alguns anys més fins a quedar reduit a un joc tradicional, sense arribar a aconseguir el rang d'esport o esport modern i amb la manca d'un club específic com es proposava, excepte la Colla Riscat. Algunes vegades entitats com l'Sport Club Català van organitzar festes esportives incorporant entre els exercicis esportius alguns partits de riscat (Mensa, 1908), però aquests fets no van ser suficients per a assolir en aquest joc una activitat de pràctica significativa.

Masferrer (1917) ja feia palesa aquesta situació de relegació del rescat i altres jocs a situacions folklòriques i de baix prestigi. Així, tot i els intents per a recuperar el joc, tal com proposava Elias «el corredisses» $\mathrm{i}$ altres personatges, destacant-ne els múltiples beneficis i avantatges -com el de no requerir un alt nivell de condició física i també el de ser un joc idoni per a tots dos sexes-, el rescat gairebé va desaparèixer de la pràctica esportiva catalana.

A tall d'exemple, es destaca un dels múltiples crits per a la pràctica del rescat, en una notícia de 1919 apareguda a La Veu de Catalunya:

Mentrestant, el que hauria de ser el nostre joc nacional, escaient als dos sexes, roman limitat als esbargiments d'escoles modestes. Parlem del joc de riscats, que no necessita sinó una intel-ligent codificació per a esdevenir un joc tan apassionat i tan interessat com el de foot-ball. I no cal dir que el joc de riscats (que recomanem a la sol-licitud del nostre il-lustre Corredisses) no necessita, com el football, musculatures excepcionals ni prades blanes per a anar-hi de corcoll. Aquests jocs de moda, d'origen estranger, franc o anglès, pero codificats pels anglesos, eren també d'origen popular, i només per la seva perfecta reglamentació han triomfat. L'amic Corredisses té la paraula! (Georgina, 1919, p. 366).

El mateix autor analitza també el valor moral extraordinari del joc destacant-ne la disciplina requerida i l'abandonament de la individualitat pel de la collectivitat, juntament amb aquesta catalanitat que simbolitzava (Elias, 1917; Georgina, 1919).

Tot i la influència del futbol, el joc del rescat va continuar sent popular durant algunes dècades més, ja que, quan mancava la pilota, el tradicional i popular joc continuava essent el favorit.

Finalment, cal comentar que el joc del rescat -en part gràcies a aquestes veus que el promocionaven- va esdevenir popular en els models renovadors catalans d'inicis del segle passat. Les iniciatives anaven encaminades a promoure el joc tradicional envers la gran acollida i expansió dels esports estrangers. Cal destacar l'Escola del Mar, en la qual el pedagog català Pere Vergés inclou el joc organitzat com un element de la vida social i del projecte educatiu del centre. Un d'aquests jocs tractats fou el rescat, que, a la vegada, era l'activitat més motivant per al jovent (Vergés, 1932, 1933, 1947, 1957). És curiós remarcar que en aquest centre, a més, es creen diversos clubs i associacions promogudes pels alumnes (Vergés, 1947), emulant l'escola anglesa i 
simbolitzant un model associatiu a petita escala: l'escola (Brasó \& Torrebadella, 2014).

No obstant això, en aquella època el rescat tenia molt difícil la seva supervivència, ja que a la capital catalana un nou esport molt més espectacular anomenat football prenia carta de naturalesa entre els aficionats a l'educació física (Torrebadella, 2012c). La força amb què va irrompre el futbol i altres esports de moda va reduir el nombre d'aficionats al rescat, els quals, en poc temps, van quedar arraconats a una posició d'indiferència social.

\section{Causes de la relegació del rescat a joc popular}

En l'actualitat, el rescat gairebé ha desaparegut del context social i educatiu i, si en algun cas es tracta, principalment des de la matèria d'educació física en els centres escolars, es fa com el que ha esdevingut: un joc tradicional o popular.

Com s'ha vist, tot i que a inicis del segle xx semblava que hi havia un moviment per a recuperar i practicar el joc, fins i tot per a convertir-lo en un esport, aquestes veus es van anar diluint i van quedar oblidades. El motius són diversos. El primer d'ells fa referència a l'explosió i bona acollida que van tenir els esports forans, sobretot el futbol. Aquestes activitats provinents d'Anglaterra tenien la particularitat de tenir un reglament perfecte, a diferència del rescat, en el qual, com s'ha comprovat, contínuament hi havia disputes, tant entre equips com pel que fa a les situacions arbitrals mal gestionades (Bartrés, 1934, Georgina, 1919; Vergés, 1932). La percepció de l'impacte del futbol sobre els jocs nacionals com el rescat, queda evidenciat en una de les cròniques d'enaltiment de la propaganda de l'educació física publicada en terres lleidatanes en un suggestiu article que porta per nom De re deportiva, i en el qual, entre altres qüestions, es tracta la similitud del futbol amb el rescat, que vindria a ser un futbol sense pilota:

Recordem el primer partit de foot-ball que vegerem a la primavera del any 99 del segle passat, si no ens es infidel la memòria. Fou als voltants de Barcelona, a la Font de Casanovas, quant aquelles encontrades començaren a poblar-se i se reconstruïa el que més tard fou hotel i avui casino. ¿Per què va interessar-nos? ¿Quines foren les circumstàncies que determinaren el que tornéssim el diumenge següent i l'altre...? Indubtablement lo joc tenia per nosaltres quelcom d'atraient; era el nostre joc de riscats portat a cap d'una manera més complicada i per homes que també nos semblaven d'una certa complicació, molts parlaven llengua estranya i anaven habilitats de manera mes estranya encara. Més de quatre vianants s'apropen al camp creient-se se les havien amb uns quants xiflats; vint anys després los xiflats, actius i espectadors s'han multiplicat com la descendència de Jacob (Man, 1921, p. 19).

A més, en el cas del joc, diferents zones de Catalunya se l'havien fet seu, li havien posat un nom $i$, tot $i$ que en termes generals la dinàmica fos similar, hi havia regles diferents. Aquests fets, juntament amb la complexitat normativa esmentada derivada de la seva lògica interna -molt major que el futbol (Parlebas, 2001)-, van impedir que sobrevisqués.

Pel que fa al seu caràcter motriu, com citen Lagardera i Lavega (2003), el rescat té un alt grau de complexitat sociomotriu (Guillemard, Marchal, Parent, Parlebas, i Schmitt, 1988) que es reflecteix en la varietat d'estratègies que poden adoptar els equips i, com cita Sabater (1918), en el grau de disciplina que exigeix el joc. En paraules de Borja, «exige una disciplina y sumisión a uno que hace de jefe, si se quiere llevar ventaja en el juego» (1982, p. 109).

Però aquesta complexitat en la lògica interna va ser un dels problemes que va tenir el joc per a la seva supervivència. Així, la no-possibilitat d'estipular un reglament tan precís com el que tenien els esports provinents d'Anglaterra va ser un greu problema, fet que implicava que, per a poder aplicar el reglament, hi havia d'haver també bona voluntat dels propis participants. Masferrer (1917, p. 6), en un escrit narrant l'oblit del riscat i altres jocs, ja feia notar aquesta manca de normativa del joc i parlava de «nuestros deportes sin reglamentación alguna y solo atemperados a las leyes transmitidas de la palabra de generación en generación».

Juntament amb aquest fet, la bellesa i el profit que tenia el futbol en l'àmbit de la salut i la seva fàcil aplicabilitat a l'escola van propulsar la seva pràctica (Elias, 1917) i van deixar de banda el joc autòcton.

Albert Serra (1907, p. 151) volia polaritzar el futbol i apropar-lo als joves de Barcelona. Citava que el futbol encara no s'entenia i que s'hi jugava sense l'esportivitat que caracteritzava els equips amateurs d'Anglaterra, França, Alemanya o Itàlia. Opinava que es tractava de «una lucha sana y violenta» i que los «raros golpes que podían recibirse accidentalmente entre los jóvenes corteses y bien educados sirven más bien para templar el cuerpo y el alma del atleta, quien pone en juego en él todas las partes del organismo». Argumentava que la destresa del futbol equivalia a l'organització dels escacs, amb els quals tenia similitud i en els quals es desenvolupava un joc de forma matemàtica i acadèmica:

Debemos pues inclinar a nuestros adolescentes que por las condiciones físicas de la raza han demostrado que son perfectamente aptos para este juego, hacia las practicas de asociación, pero bajo la dirección al principio del maestro gentlemen, esto es, que les eduquen en la destreza del juego, ya que por la parte brutal del mismo sobrado se aprende más tarde, si es conveniente echar mano de ella (Serra, 1907, p. 152)

Encara que Josep Elias va ser el principal promotor del rescat d'aquesta època, val a dir, però, que també va esdevenir el principal promotor del futbol escolar, esport que va ser, com s'ha dit, la principal causa del recés del rescat. Tot i això, Elias no renunciava al popular joc: «Hi ha sports purament nostres, com el rescat, 
que poden ser un bell punt de partida per iniciar la mainada en aquests jocs col-lectius, però per sobre tots hi ha el football.» (Elias, 1917, p. 311). A més a més, en la primera obra monogràfica del futbol espanyol, Elias (1914) va afirmar que:

Si hay necesariamente que cultivar nuestros músculos, vigorizar nuestra voluntad dormida en nuestro pueblo; si queremos aspirar a ser fuertes y equilibrados por práctica de los deportes, pocos encontramos que encierren tal cúmulo de ventajas y perfecciones desde diferentes puntos de vista, como el moderno football (Elias, 1914, p. 19).

Tanmateix, el joc de riscat va resitir i, de tant en tant, s'aixecaven veus recordant la seva identificació tradicional amb el poble. Josep Maria Romagosa exhortava la consrucció d'un estadi per a celebrar unes Olimpíades a la comarca del Penedès, amb la finalitat de recercar els esports genuïnament catalans per a ser portats al públic com a espectacle al costat dels esports forasters:

¿No tenim, per exemple un joc de la barra -en altres punts anomenat riscat- que a tots ens ha servit de diversió, i que amb les pertinents modificacions podria servir per a disputar-se la victòria dos bàndols fent-nos admirar els recursos inexhauribles de la previsió, l'astúcia i l'audacia? (Font d'Horta, 1921, p. 2).

Un altre agitador del joc fou Antoni Rovira i Virgili que, des de la Revista de Catalunya, presentava la proposta d'un amic per a rescatar el rescat, del qual deia que era un joc molt conegut i practicat al pati de les escoles. S'opinava «que el rescat indígena podria desbancar, a casa nostra el futbol exòtic», que amb la constitució d'un club de Rescat i d'una Federació Catalana de Clubs de Rescat $\mathrm{i}$ altres elements, com tenen els esports actuals, s'encendria també la gran febre «rescatista» (Rovira, 1926, p. 388).

\section{Conclusió}

Fins a finals del segle xIx i inicis del xx, el rescat és practicat pel jovent a les hores de pati de l'escola o de manera lliure; per tant, és un dels molts jocs que es practiquen utilitzats pel jovent per a la seva recreació i oci. Però, durant els inicis del segle $\mathrm{xx}$, amb la importació dels esports estrangers, com el futbol, comença a aparèixer un moviment que potencia la pràctica per fer front a aquesta invasió esportiva anglosaxona. Aquest moviment, iniciat per l'Associació Catalana de Gimnàstica, en la qual es forma la Colla Riscat, i juntament amb altres personatges particulars vinculats a l'associacionisme esportiu català, que plasmen les seves idees en revistes i premsa de l'època, tenen l'objectiu d'aconseguir que el joc es pugui convertir en un esport. La justificació de la seva pràctica vindrà fonamentada principalment pel caràcter català, tot i que també es va intentar mantenir per altres valors, com la possibilitat de participació sense requerir un alt grau de condició física. Per tant, era una activitat altament participativa, abraçant una majoria molt àmplia de la població. A més, diversos personatges el consideraven com un esport «superior», tant pel que fa a la salut com pel que fa a la cognició i pel que fa a l'estat d'ànim.

Es comprova però, que a partir del primer terç del segle $\mathrm{xx}$, el rescat va perdent el poc impuls que tenia $\mathrm{i}$ va quedant relegat a un joc popular i gairebé oblidat. Una de les causes és la complexitat a l'hora de controlar i arbitrar els partits, que vénen determinades per la complexitat sociomotriu del joc i la no- perfecció reglamentària (Bartrés, 1934; Georgina, 1919; Masferrer, 1917; Parlebas, 2001).

Aquesta dificultat en l'arbitratge, que fa necessari el fair-play per part dels participants a més de l'autogestió de les emocions per a aplicar el reglament correcte, fa del joc una possible activitat beneficiosa en l'àmbit escolar i vetlla perquè els alumnes esdevinguin més participatius i més responsables dels seus actes, com proposà el pedagog Pere Vergés en el seu model educatiu a l'Escola del Mar. D'altra banda, però, aquesta impossibilitat de portar a la pràctica la normativa de manera perfecta, a causa de la quantitat i simultaneïtat d'interaccions motrius en poc temps, fa que no tingui cabuda en la seva institucionalització.

Però el fet més destacable que va apartar el rescat de la societat de principis del segle xx va ser l'expansió de la pràctica anglesa de moda, el futbol, que va impedir-ne la popularitat i la possibilitat que esdevingués un esport.

\section{Referències}

Andarín (1900, novembre 18). Colla Excursionista. Stadium, 729.

Antich, J. (1904, febrer 3). La Medicina Moderna XIV. Los Deportes. La Vanguardia, 4.

Arnal, M. (1900, octubre 28). Colla Excursionista. Stadium, 677.

Artells, J. J. (1972). Barça, Barça, Barça. F. C. Barcelona, esport i ciutadania. Barcelona: Laia.

Balcells, A. (1992). Historia del nacionalisme català, dels orígens als nostres temps. Barcelona: Generalitat de Catalunya.

Balius, R. (1982). Josep Elias i Juncosa. Apunts d' Educació Física i Medicina Esportiva, 19(75), 209-216.

Bardina, J. (1908). Escola de Mestres. Memòria del curs 1907-08. Barcelona: Escola de Mestres.

Bartrés, R. (1934, maig 24). Cròniques. Garbí, 6.

Blai (1919, maig 24). Anotacions. Riscats. La Veu de Catalunya, 8.

Borja, M. de (1982). El joc: eina pedagògica a Catalunya. Barcelona: Hogar del Libro.

Borrell, J. \& Sanvicén, P. (1998). La Renaixença a Lleida. Lluís Roca i Florejachs i Josep Pleyan de Porta. Lleida: Edicions Universitat de Lleida.

Bourdieu, P. (2008). Cuestiones sociales. Madrid: Akal. Brasó, J. \& Torrebadella, X. (2014). El joc del rescat a Catalunya. Un projecte educatiu a l'Escola del Mar de Pere Vergés. Temps d’Educació, (47), 191-212. 
Caillois, R. (1986). Los juegos y los hombres. México: Fondo de Cultura Económica

Capdevila, J. (2012). Modernització i crisi comunitària. Estudis d'etnohistòria rural. La Catalunya occidental en el canvi dels segles XIX $i$ XX. Lleida: Servei de Publicacions de la Universitat de Lleida.

Corredisses (1900, juny 9). Gazeta de Sport. La Veu de Catalunya, 4.

Corredisses (1902, setembre 19). Gaceta de Sports. El Joch del futbol. La Veu de Catalunya, 2.

Coubertin, P. (2004). Lliçons de pedagogia esportiva. Vic: Eumo Editorial.

Delgado, B., Cortada, R., González-Agàpito, J. \& Lozano, C. (1980). Joan Bardina, un revolucionario de la pedagogía catalana. Barcelona: Universidad de Barcelona.

Elias, J. (1917). Pedagogia esportiva (acabament). Quadenrs d'Estudi, 1(4), 307-313.

Elias, J. (1901, agost 1). Sport. Lo skating a tot arreu. Lo patinatje a Barcelona. Actualitat. La Ilustració Llevantina, 1.

Elias, J. (1900, noviembre 1). Sport. La Ilustració Llevantina, 1-2.

Elias, J. (1902). La Vida física. En J. B. Batlle, Calendari català per l'any 1902, (pp. 154-156). Barcelona: Llibreria Joan Bta. Batlle.

Elias, J. (1904). L'any esportiu. En J. B. Batlle, Calendari català per l'any 1904 (pp. 119-121). Barcelona: Llibreria Joan Bta. Batlle.

Elias, J. (1905). L'any esportiu. En J. B. Batlle, Calendari català per l'any 1905 (pp. 118-121). Barcelona: Llibreria Joan Bta. Batlle.

Elias, J. (1914). Football asociación. Barcelona: Imp. R. Tobeña.

Elias, J. (1903, setembre 20). Sports. La Ilustració Catalana, 259.

Elias, J. (1907, juliol 28). Els sports y la dona. La Ilustració Catalana, 18.

Elias, N. \& Dunning, E. (1986). Deporte y ocio en el proceso de la civilización. México: Fondo de Cultura Económica.

Elias, R. (1992). Josep Elias i Juncosa «Corredisses», un precursor de l'olimpisme català. Barcelona: Generalitat de Catalunya, Departament de la Presidència, Secretaria General de l'Esport.

Esteve, J. \& Belvitges, J. (1803). Diccionario CatalánCastellano-Latino, t. I. Barcelona: Oficina Tela Pla Viuda.

Estos días en otros tiempos (1917, març 17). Stadium, 166.

Extrangerisme (1901, abril 12). L'esquella de la Torratxa, 262.

Farnés, S. (1902). Sempre Avant. En Batlle, Joan Bta: Calendari català per l'any 1902 (pp. 5-6). Barcelona: Llibreria Joan Bta. Batlle.

Federación Gimnástica Española (1900, setembre 28). Fiestas de la Federación Gimnástica Española. La Vanguardia, 6.

Federación Gimnástica Española (1902). Ferias y Fiestas populares de Ntra. Sra. de las Mercedes. Programa y Re- glamentos de los concursos de la Federación Gimnástica Española. Barcelona: Imp. José Cunill.

Fiesta Atlética del Catalá Sport Club (1908, novembre 30). Los Deportes, 444.

Fiestas de la Federación Gimnástica Española (1900a, setembre 24). La Vanguardia, 7.

Fiestas de la Federación Gimnástica Española (1900b, setembre 26). La Vanguardia, 3.

Font d'Horta [Romagosa, J. M.] (1921, juliol 17). Proses Lleus. Penedés exacra-ho. Badalota, 1-2.

Foot-ball (1900, setembre 30). Los Deportes, 616617.

Galí, A. (1985). Història de les institucions i del moviment cultural a Catalunya, 1900-1936, Obres Completes, llibre X: Institucions de Cultura Popular. Barcelona: Fundació Alexandre Galí.

Georgina (1919, abril 16). L'hora del te. D'Ací dallà, 366.

Gimnasio Solé (1904, octubre 23). Los Deportes, 682684.

Guillemard, G.; Marchal, J. C.; Parent, M.; Parlebas, P. \& Schmidt, A. (1988). Las cuatro esquinas de los juegos. Lleida: Agonos.

Hip (1917, abril 27). De les botxes al futbol. L'esquella de la Torratxa, 336-337.

Huizinga, J. (1972). Homo ludens (6 ed.). Madrid: Alianza.

J. B. (1902, febrero 9). Remitido (sobre foot-ball) Sr. Director de Los Deportes. Los Deportes, 89-90.

La cuna del C. N. Barcelona (1927, novembre 15). La Vanguardia, 19.

La Salle de Rochemaure (1909). Gran Festa Sportiva. Aurillac: Imp. Moderrne.

Labernia, P. (1865). Diccionari de la llengua catalana. Barcelona: Espasa Germans.

Lagardera, F. (1992). De la aristócrata gimnástica al deporte de masas: un siglo de deporte en España. Sistema, (110-111), 9-36.

Lagardera, F. (1996). Notas para una historia social del deporte en España. Historia de la Educación, (14-15), 151-172.

Lagardera, F. \& Lavega, P. (2003); Introducción a la praxiología motriz. Barcelona: Paidotribo.

Man (1921). De re Deportiva. Lleida, (1), 18-19.

Mandell, R. (1986). Historia cultural del deporte. Barcelona: Bellaterra.

Masferrer, N. (1917). Prólogo. Mirando hacia atrás. En E. Navarro (1917). Álbum de Sociedades deportivas en Barcelona (pp. 5-10). Barcelona: Imp. José Ortega.

Maspons, F. (1874). Jochs de la infancia. Barcelona: Estampa de Frederich Martí y Cantó.

Mensa, M. (1908, novembre 12). Notas varias. El Mundo Deportivo, 4.

Miscelánea (1900c, desembre 2). Stadium, 765.

Miscelánea (1900a, desembre 25). Los Deportes, 125.

Miscelánea (1900b, novembre 25). Stadium, 750.

Moll, F. de B. (1951). Diccionari Català-València-Balear, t. IX. Barcelona: Gràfiques Miramar. 
Notas Locales (1900, setembre 21). La Vanguardia, 2. Notas Locales (1902, setembre 27). La Vanguardia, 2. Parlebas, P. (2001). Juegos, deporte y sociedad. Lexico Praxiologia motriz. Barcelona: Paidotribo.

Pastor, J. L. (1998). La extravagante difusión del deporte moderno. Puertas a la Lectura (4), 14-19.

Pelegrín, A. (1998). Repertorio de antiguos juegos infantiles. Madrid: CSIC.

Pons, M. (1921, juliol 9). De la vellúria. Deports. La Crònica de Valls, 2.

Programa de festejos para hoy (1902, setembre 27). La Vanguardia, 2.

Pujadas, X. (2008). Els orígens de l'esport a la Catalunya contemporània: entre la modernització del lleure i la massificació (1870-1936). En C. Santacana, (Coord.). Nadala, 2008. L'esport a Catalunya (pp. 1327). Barcelona: Fundació Lluis Carulla.

Pujadas, X. \& Santacana, C. (1992). L'esport català i el fet nacional (1900-1939). Revista de Catalunya, (65), 76-89.

Pujadas, X. \& Santacana, C. (1995). Història il.lustrada de l'esport a Catalunya, vol. I (1870-1931). Barcelona: Edita Columna, Diputació de Barcelona.

Pujadas, X. \& Santacana, C. (1997). L'esport és noticia. Història de la premsa esportiva a Catalunya (18801992). Barcelona: Col-legi de Periodístes de Catalunya.

Pujadas, X. \& Santacana, C. (2001). La mercantilización del ocio deportivo en España. El caso del fútbol (19001928). Historia social, (47), 147-168.

Pujadas, X. \& Santacana, C. (2003). El club deportivo como marco de la sociabilidad en España. Una visión histórica (1850-1975). Hispania. Revista Española de Historia, (214), 505-522.

Regàs, X. (1929, desembre 31). L'aprofitament de Montjuïc. La Publicitat, 25.

Rivero, A. \& Sánchez, R. (2011). The international British influence in the Birth of Spanish Sport. The International Journal of the History of Sport, 28(13), 1788-1809. Doi:10.1080/09523367.2011.5 94686

Rovira, A. (1926). El futbol a casa nostra. (Aspectes del problema esportiu). Revista de Catalunya, (25), 379388.

Sabater, A. (1918). Juegos infantiles. Boletín del Liceo Escolar, (113), 2-5.

Santacana, C. (2004). La Mancomunitat de Catalunya $i$ la política esportiva. Barcelona: Generalitat de Catalunya.

Sardà, F. (1908). L'sport católich. Barcelona: Lib. Tip. Católica.

Serra, A. (1907, febrero 9). El foot-ball (Conclusión). Los Deportes, 151-152.

Serra, A. (1900, juny 13). Notas Sports. La Vanguradia, 3. Serra, E. (1923). Lleida vella, jocs i esports. Boletín del Instituto General Técnico de Lérida, (6), 109-110.

Silueta del primer team Iberia Foot-ball Club (1903, febrero 1). Los Deportes, 69-70.

Societat de Catalans (1839). Diccionari catalá-castellállatí-francés-italiá, t. II. Barcelona: Imp. Joseph Torner.
Torras i Bages, J. (1910). L'atletisme cristià carta pastoral amb motiu del sant temps de Quaresma de 1910. Vic: Imp. Anglada.

Torrebadella, X. (2003). 150 anys d'esport a les Terres de Lleida (1850-2000). Generalitat de Catalunya: Lleida.

Torrebadella, X. (2011). Repertorio bibliográfico inédito de la educación física y el deporte en España (1800-1939). Madrid: Fundación Universitaria Española, Madrid.

Torrebadella, X. (2012a). Las primeras revistas profesionales y científicas de la educación física española (1882-1936). Apunts. Educación Física y Deportes, (190), 11-25.

Torrebadella, X. (2012b). Los orígenes de una ciudad olímpica: Barcelona y el asociacionismo deportivo decimonónico ante la gestación de los primeros Juegos Olímpicos. Citius, Altius, Fortius, 5(2), 91134.

Torrebadella, X. (2012c). Orígenes del fútbol en Barcelona (1892-1903), RICYDE: Revista Internacional de Ciencias del Deporte (27), 80-102. Doi. 10.5232/ricyde2012.02706

Torrebadella, X. (2013). La aportación bibliográfica de Joan Bardina a la educación física moderna (19111939). Cabás, (9), 1-22.

Torrebadella-Flix, X. \& Olivera-Betrán, J. (2013). The Birth of the Sports Press in Spain within the Regenerationist Context of the Late Nineteenth Century. The International Journal of the History of Sport, 30(18), 2164-2196. http://dx.doi.org.10.1080/09523367.20 13.854775

Torrebadella, X. \& Planas, A. (2011). Del deport a l'esport i de l'esport al deport. Molt més que una discussió terminològica. Terminàlia, (3), 22-39. Doi: 10.2436/20.2503.01.22

Torrent, J. \& Tasis, R. (1996). Història de la premsa catalana. Barcelona: Ed. Brugera.

Un Riscatista (1900a, març 18). Colla Riscat. Los Deportes, 167.

Un Riscatista (1900b, març 25). Colla Riscat. Los Deportes, 187.

Un Riscatista (1900c, abril 1). Colla Riscat. Partido celebrado el 25 de marzo en el Club Ciclista Los Deportes, 202.

Un Riscatista (1900d, abril 15). Colla Riscat, Los Deportes, 235.

Un Riscatista (1900e, juny 17). La Colla Riscat. Los Deportes, 373-374.

Un Suplente (1904, maig 24). Estos últimos días... El Mundo Deportivo, 6.

Valserra, F. (1944). Historia del deporte. Barcelona: Ed. Plus-Ultra.

Vergés, P. (1932). La Vida Espiritual a Vilamar. Barcelona: Ajuntament de Barcelona. Comissió de Cultura.

Vergés, P. (1933). Els Escacs a 1'Escola del Mar. Escacs a Catalunya, (71), 1388-1389.

Vergés, P. (1947). Libro de Evocaciones (1922-1947). Barcelona: Altés.

Vergés, P. (1957). La Escuela del Mar. Una Escuela y una vocación. Barcelona: Escuela del Mar. 


\section{El juego del «rescat» en el proceso constituyente del deporte contemporáneo en Cataluña (1900- 1926)}

Resumen. El objeto de este artículo es analizar la presencia del juego del marro en la sociedad catalana y, concretamente, en los movimientos asociativos del deporte de inicios del siglo Xx. Este estudio se ha elaborado a partir de una investigación documental de fuentes primarias, principalmente de la prensa deportiva, pero que ha contado con el apoyo de otras investigaciones recientes. A principios del siglo pasado, con la incorporación de los deportes de origen anglosajón, en Cataluña el popular juego de equipo del marro se presentó públicamente con la intención de alcanzar el nivel de reglamentación necesario para ser amparado en el proceso de deportivitzación moderno. Así, el marro, fue practicado en Barcelona por algu- nos prohombres de la cultura física, agrupándose inicialmente en la "Colla Riscat», y tratando de potenciar el carácter saludable y educativo de este juego al aire libre. Asimismo, la práctica se manifestó como expresión genuina de la catalanidad ante la invasión de las prácticas deportivas extranjeras que se estaban incorporando en Cataluña. A pesar de la propaganda, y la popularidad ancestral del marro, éste perdió el atractivo que como juego corporal había predominado en las costumbres recreativas de la población más joven. Una de las causas en la pérdida de protagonismo de la práctica se atribuye a la rápida y significativa aceptación del deporte de moda: el fútbol.

Palabras clave: "Colla del Riscat», juego del rescate, juego del marro, historia del deporte en Cataluña, fútbol 
